\title{
Editorial a convite ${ }^{1}$
}

\author{
Maria Ângela Feitosa \\ Wânia Cristina de Souza \\ Universidade de Brasilia
}

Este número especial de Psicologia: Teoria e Pesquisa é comemorativo dos 10 anos de funcionamento dos quatro Programas de Pós-graduação do Instituto de Psicologia da Universidade de Brasília, quais sejam, os Programas de Ciências do Comportamento; de Psicologia Clínica e Cultura, de Psicologia do Desenvolvimento e Escolar, e de Psicologia Social, do Trabalho e das Organizações.

Foram convidados editores associados especiais para esse número, não vinculados à UnB. Eles avaliaram os artigos submetidos e selecionaram os que seriam publicados, de acordo com o limite máximo de seis artigos por Programa e de apenas um artigo por docente do Programa ao qual está vinculado. Os critérios se basearam na contribuição científica do manuscrito, na presença de parcerias nacionais e internacionais na elaboração do artigo, e na qualidade de sua redação.

O vir a ser dos Programas se iniciou com uma provocação pela CAPES, desconfortável com o tamanho e a formatação do então Programa de Psicologia, que em 2003 já contava com 68 docentes distribuídos em várias linhas e projetos de pesquisa. Em 2004 iniciou-se um movimento duplo no Instituto de Psicologia, de um lado procurando aperfeiçoar o Programa vigente e de outro buscando outras formatações, com o possível desdobramento do Programa. À época, Renato Janine Ribeiro era presidente da CAPES, Oswaldo H. Yamamoto o Coordenador da Comissão da Área de Psicologia na CAPES, Márcio M. Pimentel o Decano de Pesquisa e Pós-graduação (DPP) da Universidade de Brasília, Maria Angela G. Feitosa a Diretora do Instituto de Psicologia, e Norberto de Abreu e Silva o Coordenador do Programa de Pós-graduação em Psicologia. Foi necessária ampla interlocução entre CAPES, DPP e Conselho do Instituto de Psicologia, pois a transformação de um Programa muito grande e sem precedentes, para os parâmetros da área, em quatro Programas de médio porte era um processo complexo. Essa especificidade exigiu a criação de normativa que resguardasse principalmente a condição dos estudantes ativos no Programa, em inúmeros aspectos acadêmicos, sendo-lhes facultado, caso a caso, concluírem o curso no Programa de vínculo original ou se transferirem para o novo Programa a que seu trabalho acadêmico melhor se ajustasse.

Com a decisão preliminar de constituição de quatro novos Programas, entraram em campo novos atores que constituíram os grupos de trabalho para a sua concepção, seus regulamentos próprios e sua proposição junto à CAPES, cada um deles emergindo a partir de uma das áreas de concentração do Programa de Pós-graduação em Psicologia. O Programa de Psicologia, que havia iniciado suas atividades em 1988 com o acréscimo do doutorado aos mestrados já existentes, realizou sua última seleção em 2005 e encerrou formalmente

1 As autoras agradecem às Coordenadoras dos Programas de Pósgraduação, à Editora-chefe e ao Editor-adjunto de Psicologia: Teoria e Pesquisa pela disponibilização de dados. suas atividades em 2009, quando o último estudante apresentou seu trabalho de conclusão. Em 2005 os novos Programas foram aprovados pelo Conselho do Instituto, e no início de 2006 pelo Conselho de Ensino Pesquisa e Extensão da Universidade, com autorização para abertura imediata de processo seletivo. Os primeiros coordenadores foram Elenice Seixas Hanna à frente do Programa de Ciências do Comportamento, Glaúcia Ribeiro Starling Diniz à frente do Programa de Psicologia Clínica e Cultura, Maria Auxiliadora da Silva Campos Dessen à frente do Programa de Processos de Desenvolvimento Humano e Saúde, e Jairo Eduardo Borges Andrade à frente do Programa de Psicologia Social, do Trabalho e das Organizações.

Atualmente estão credenciados nos quatro programas um total de 82 professores, sendo 69 do quadro permanente (dos quais sete também orientam em outros programas) e 13 colaboradores. Dez bolsistas de pós-doutorado contribuem com aulas e orientações de estudantes nos cursos de Mestrado e Doutorado. Do total de estudantes, atualmente 150 estão matriculados no Mestrado e 164 no Doutorado. São coordenadores Elenice Seixas Hanna à frente do Programa de Ciências do Comportamento; Elaine Neiva à frente do Programa de Psicologia Social, do Trabalho e das Organizações, Maria Inês Gandolfo Conceição à frente do Programa de Psicologia Clínica e Cultura, Fabrícia Borges à frente do Programa de Processos de Desenvolvimento Humano e Saúde; e Wânia Cristina de Souza é a Diretora.

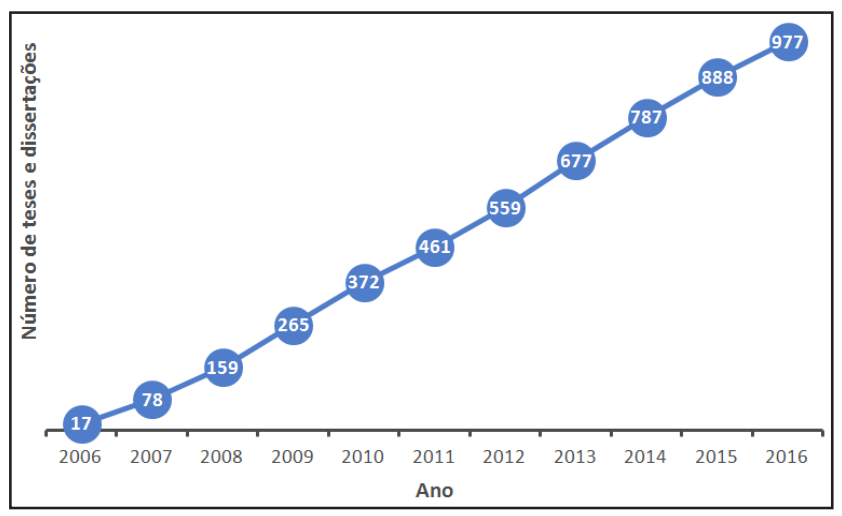

Figura 1. Teses e dissertações acumuladas ao longo do período de 2006 a 2016, agregando-se as defesas ocorridas nos quatro Programas de Pós-graduação do Instituto de Psicologia da Universidade de Brasília.

Conforme a Figura 1 mostra, os quatro Programas de Pósgraduação do Instituto de Psicologia acumulam, concluída sua primeira década de funcionamento, perto de 1000 teses e dissertações defendidas, uma contribuição expressiva para a formação de pesquisadores nas diferentes áreas da Psicologia no país. Observa-se um padrão regular de produção, sugerindo condições estáveis para seu funcionamento. A existência de defesas já no primeiro ano dos Programas 
reflete a absorção de estudantes do antigo Programa de Pósgraduação em Psicologia para um ou outro Programa atual.

Ao longo desta trajetória os Programas honraram o compromisso histórico do Instituto de Psicologia com a revista Psicologia: Teoria e Pesquisa que é editada desde 1985 e teve como primeira Editora a Professora Emérita Dra. Eunice Maria Lima Soriano de Alencar. A revista mantém sua independência editorial, responde academicamente ao Colegiado dos Cursos de Pós-Graduação do Instituto de Psicologia e administrativamente ao Conselho do Instituto. Em sua atual configuração a direção da revista é composta por um Editor Chefe, um Editor Adjunto, um Secretário de Editoração e 16 Editores Associados. Na composição do corpo editorial, $50 \%$ estão vinculados aos programas de pós-graduação do Instituto de Psicologia; 25\% a outras instituições de ensino e pesquisa nacionais; e $25 \%$ a instituições de ensino e pesquisa internacionais.

Atenta à importância de modernização e internacionalização, Psicologia: Teoria e Pesquisa hoje disponibiliza a modalidade de publicação continuada e aberta, em versão eletrônica; redefiniu seu escopo, passando a publicar artigos em quatro grandes áreas: Ciências do Comportamento; Psicologia do Desenvolvimento e Escolar; Psicologia Clínica e Cultura e Psicologia Social, do Trabalho e das Organizações, refletindo assim o perfil de capacitação em pesquisa dos quatro programas de Pós-Graduação; e ampliou as opções de língua de publicação, passando a publicar trabalhos preferencialmente em português, inglês, espanhol e francês, e eventualmente em alemão e italiano.

Com sua vasta contribuição nos últimos 31 anos, Psicologia: Teoria e Pesquisa vem publicando, de forma ininterrupta, artigos com o objetivo de divulgar pesquisas de grande impacto científico para a área da Psicologia. $\mathrm{O}$ reconhecimento de sua atenção constante à qualidade está refletido nas avaliações realizadas pela CAPES, que lhe têm conferido desde 2010 a nota QUALIS A1 na área de Psicologia. Está também refletido em avaliações internacionais, como a do Scimago Journal Rankings, que a situou entre os 10 mais bem classificados periódicos brasileiros na área da Psicologia.

O perfil dos 24 artigos que compõem o número especial representa a contribuição de 64 diferentes autores. Destes, 49 são vinculados à Universidade de Brasília, e 15 a 12 outras instituições, das quais sete no exterior. Dentre os autores, 20 são estudantes correntes ou recém-egressos dos Programas. Mas a sua participação se torna mais acentuada quando constatamos que uma parte dos autores que se identifica pelo vínculo atual a outras instituições brasileiras é de egressos inseridos no mercado de trabalho em universidades ou secretarias de governo, resultando em que, de fato, a maioria dos artigos reflete coautoria entre pesquisadores e estudantes. Reflete ainda o, papel dos egressos na formação de redes de pesquisa. $\mathrm{O}$ financiamento identificado por agências de fomento é preponderantemente federal (CAPES e CNPq), com preocupante ausência da FAPDF, o que mereceria análise. Em seu conjunto, os artigos indicados pelos Editores Associados estão vinculados a todas as 14 linhas atuais de pesquisa em cada área de concentração de cada Programa, mostrando, portanto, uma cuidadosa representatividade dos temas de pesquisa sendo desenvolvidos no Instituto de Psicologia.

A natureza da contribuição que os trabalhos apresentam está concentrada em relatos de pesquisas executadas em diferentes ambientes (do laboratório ao campo, à clínica, à organização, à sociedade e seus grupos e diferentes culturas), e empregando delineamentos e métodos diversificados (experimentais, observacionais, correlacionais, estudos de casos - clínicos ou organizacionais); em proposições de ferramentas de pesquisa para diferentes temas baseados em relatos de pesquisa; em proposições de estratégias de intervenção em diferentes áreas de atuação da psicologia baseadas em estudos de caso; e em estudos empíricos e teóricos que buscam o avanço do conhecimento sobre processos psicológicos. Os objetos específicos de pesquisa são muito variados. Para apresentá-los, buscamos encontrar eixos temáticos, desconsiderando recortes por opção teórica ou metodológica, por entendermos que a diversidade dos artigos nos propicia um exercício interessante a respeito de como objetos podem ser complexos e requerer dimensões multifacetadas de estudo.

A preocupação com a educação superior está presente nos trabalhos de Borges, Araújo e Amaral, sobre variáveis que contribuem para o desenvolvimento da identidade da professora com foco na relação dialógica entre o estudante e o professor em sala de aula; de Chagas e Pedroza, sobre patologização e medicalização do estudante universitário, impactando políticas educacionais e ecoando práticas já identificadas na educação básica; e de Marinho-Araújo e Almeida sobre o conceito de competência analisado na perspectiva histórico-cultural do desenvolvimento humano, e sua utilização para avaliar a formação no ensino de graduação.

A educação básica é objeto de aplicação potencial no trabalho de Medeiros e Flores, sobre estratégias promotoras de leitura com compreensão entre estudantes do ensino fundamental; e de Mieto e Barbato, sobre como a professora em sala de aula inclusiva do ensino fundamental participa do processo de implementação da política pública de inclusão, focando nas inter-relações entre interpretações de si e do outro e de situações e atividades no contexto escolar.

O mundo do trabalho no Brasil é escrutinado em diferentes contextos, nos artigos de Bendassolli, Borges-Andrade, Gondim e Makhamed, que investiga o poder preditivo das competências empreendedoras sobre o desempenho de profissionais nas indústrias criativas, ligadas a expressões culturais e com impacto econômico, com recomendações para as agências envolvidas em treinamento empresarial; de Coelho, Antloga, Maia e Takaki, sobre qualidade de vida no trabalho e crenças de autoeficácia geral, com um estudo de caso na Polícia Militar do Distrito Federal, sendo qualidade de vida compreendida com base em um continuum de representações dos trabalhadores sobre seu contexto de trabalho; e de Franco, Neiva, Nery e Demo, que investiga, em organizações públicas, as relações entre os atributos do contexto de mudança, atitudes e bem-estar dos trabalhadores durante o processo de mudança organizacional, chamando atenção para a importância do contexto organizacional para as respostas dos indivíduos à mudança, e do planejamento estratégico para a mudança organizacional. 
A contribuição para a compreensão de pessoas ou grupos com demandas especiais e seu acolhimento pela família, pela escola ou pelo profissional de saúde está representada nos trabalhos de Fleith, sobre fatores promotores de criatividade, entre crianças frequentando o ensino fundamental, atentando para as inter-relações entre características da família, da escola, e da motivação da criança para o desenvolvimento do superdotado; de Juras e Costa, sobre o perfil e a evolução dos papéis de conjugalidade e parentalidade em famílias separadas de baixa renda e com filhos pequenos, com atenção a competências, recursos e potencialidades da família potencialmente promotoras de reorganização familiar mais adequada a seus membros; de Monteiro, Silva e Ratner, sobre a descoberta do diagnóstico de surdez e seu efeito iatrogênico, e como este diagnóstico leva a reconfiguração das relações parentais, apontando implicações para políticas públicas em saúde e educação; de Tafuri e Safra, sobre a especificidade da relação entre o cliente autista e o terapeuta, e analisa a contribuição da perspectiva fenomenológica de M. Henri para compreender a interpretação verbal com crianças autistas como uma ferramenta para criar a relação de transferência na terapia psicanalítica; e de Prestes e Feitosa, sobre a dislexia de desenvolvimento e sua relação com habilidades linguísticas e de percepção auditiva, com implicações para estratégias de prevenção, diagnóstico e intervenção.

A contribuição para o desenvolvimento, análise crítica e validação de ferramentas de pesquisa, de diagnóstico e de atuação profissional está representada nos trabalhos de Camargo e Mendes sobre o uso induzido de ferramentas, como estratégia de enriquecimento ambiental para redução de estresse em macacos mantidos em cativeiro; de Faiad, Pasquali e Primi, que apresenta o processo de construção e evidências de validade do Teste de Reação à Frustração Objetivo, construído a partir de uma versão projetiva, identificada como Teste de Reação à Frustração Projetivo (TRFP), e atentando para a utilização potencial na avaliação de reações a frustração nas áreas de saúde e trabalho; de Janczura, Castilho, Keller e Oliveira, que apresenta normas de associação livre de palavras do português, relevantes para o desenvolvimento de pesquisa sobre diferentes processos cognitivos e para o desenvolvimento de materiais pedagógicos e aplicativos; de Neubern sobre a comunicação hipnótica, revisitando sua compreensão e buscando promover uma aproximação teórica entre a iconicidade e a perspectiva complexa da comunicação hipnótica, em contexto de atuação terapêutica; e de Porto e Ferreira, sobre o desenvolvimento e testagem empírica da estrutura interna de uma escala de valores organizacionais, adotando como modelo de referência a teoria de valores culturais, relevante para instrumentar identificação de diferentes padrões de configurações culturais, para fins de diagnóstico e em estudos que identificam antecedentes, consequentes e mediadores gerais da cultura organizacional.

Tópicos candentes na sociedade e como eles se configuram no contexto brasileiro estão representados nos trabalhos de Carneiro, Torres e Ekman, sobre a influência de estereótipos sobre parlamentares e contágio comportamental na participação política, numa perspectiva transcultural, empregando modelagem por equações estruturais, e consolidando evidência de que o conceito dos Estereótipos pode ser usado para entender o ponto de vista dos cidadãos, brasileiros inclusive, sobre os parlamentares, útil para predizer participação política; de Catunda, Seidl e Lemétayer, sobre preditores da qualidade de vida de pessoas vivendo com HIV/AIDS, hipotetizando que a influência da percepção da doença sobre a qualidade de vida é mediada por estratégias de enfrentamento, e sistematizando os dados em um modelo de equação estrutural; de Conceição, Cardona, Assis, Mohr, Sudbrack e Strike, sobre usuários de crack, procurando descrever o perfil sociodemográfico, a motivação para uso e o padrão de uso de usuários que buscam tratamento público, como subsídio para o desenvolvimento de políticas de prevenção e tratamento; e de Pedrosa e Zanello, sobre a violência contra a mulher, focado na avaliação de percepção, crenças e conhecimentos, entre profissionais de saúde, sua relação com políticas públicas pertinentes, e com um olhar na formação de profissionais para atuação na área.

A ampliação do conhecimento básico sobre processos psicológicos e sobre sua transformação em metodologias de ensino está representada no trabalho de Hanna, Huber e Natalino, sobre o ensino de leitura musical, tomando o comportamento musical como um tipo de comportamento verbal e utilizando o paradigma de equivalência de estímulos; e de Pontes e Abreu-Rodrigues sobre variáveis que afetam o reaparecimento de respostas previamente extintas em humanos, onde está implícita a preocupação com a generalidade interespecífica de aspectos da aprendizagem de operantes.

Congratulamo-nos com os Programas Pós-graduação em Ciências do Comportamento; em Psicologia Clínica e Cultura, em Psicologia do Desenvolvimento e Escolar, e em Psicologia Social, do Trabalho e das Organizações pelo demonstrativo de responsabilidade para com a formação de docentes para o ensino superior e de pesquisadores independentes, e para com a produção de conhecimento científico em Psicologia. Congratulamo-nos com os leitores pela oportunidade de leitura de trabalhos tão diversos e instigantes. 